Int. J. Dev. Biol. 58: 909-916 (2014)

doi: $10.1387 / \mathrm{ijdb} .140324 \mathrm{TL}$

\title{
Evolution of maternal egg size effects in sister salamander species
}

\author{
TOBIAS LANDBERG*** \\ Biology Department, Arcadia University, Glenside, PA, USA
}

\begin{abstract}
Egg size varies genetically and with the maternal environment. It is correlated with and can act as a resource fueling variation in many other key life history traits. This study examined hypotheses about how plastic responses of offspring to yolk variation evolve (and contribute to phenotypic evolution) when maternal investment in egg size evolves. I used a split-clutch, controlled, surgical experiment with a longitudinal (repeated-measures) design to examine the effects of yolk removal on sister salamander species with distinct egg and larval phenotypes. Yolk removal had large effects in the derived larger-egged species, $A$. barbouri, and greatly reduced effects in $A$. texanum. Early hatching and smaller larval body size was only found in $A$. barbouri and survival rates decreased more in $A$. barbouri. These results provide strong experimental evidence that as female salamanders evolve greater yolk investment in each egg, offspring coevolve an increased magnitude of phenotypic plasticity in response to yolk variation across a suite of life history traits. Yolk therefore acts as an integrator of phenotypes that allows females to modify modules of life history traits together (facilitating adaptation). When organisms invade new environments, complex integrated phenotypes may evolve via correlated responses to increased maternal investment, yet individual traits can be coupled or decoupled to yolk quantity variation in different species.
\end{abstract}

KEY WORDS: ovum, propagule size fitness function, experimental embryology, yolkectomy

\section{Introduction}

Egg size varies dramatically in amphibians - within and between clutches, individuals, populations and species (Salthe 1969; Kaplan, 1980; Duellman and Trueb 1986; Wells 2007). This maternal variation has been the focus of theoretical and empirical research because of its potential to affect fitness and evolution (Kaplan and Cooper 1984; Bernardo 1996a; Nussbaum 2003). Females have a finite amount of space within the body for total clutch volume, and therefore increases in allocation to individual eggs limit the total number of eggs she can produce at one time (Kaplan and Salthe 1979). The evolutionary outcome of this trade-off is largely determined by the complex phenotypic effects related to egg size and their impacts on offspring growth and survival (models like Smith and Fretwell 1974). However, often, a single optimum egg size does not appear to evolve; rather, egg size varies within clutches as a bet-hedging strategy (Kaplan and Cooper 1984; Bernardo $1996 b)$. This range of egg sizes ensures a phenotypically diverse set of offspring that may be well-suited to unpredictable and heterogeneous environments.

Egg size variation can lead to multiple effects on phenotypes later in development. When a single female produces eggs with different yolk reserves, the effects of differential provisioning can be considered to result from phenotypic plasticity: developmental programs diverge due to differences in the maternally-endowed resource environment. The suites of traits affected by resource availability are integrated through their plastic responses to yolk availability. Such modular responses to egg size variation can integrate potentially adaptive plastic responses by affecting multiple co-dependent traits simultaneously (Lancaster et al., 2010) and contribute to evolution of life history modes (Sinervo and McEdward 1988; Allen 2012). Developmental plasticity in response to egg size variation should therefore be expected for organisms that have high natural variation in the yolk content of their eggs.

Resolving the conundrum of which traits are directly affected by egg size and how species differ in their response to egg size variation is difficult because organisms with different egg sizes may also have other physiological and genetic differences. Even comparisons between individual females' clutches within a population could be

Abbreviations used in this paper: ANOVA, analysis of variance.

*Address correspondence to: Tobias Landberg. Biology Department, Arcadia University, 450 S. Easton Rd. Glenside, PA, 19038, USA. Tel: 215-572-2885.
Fax: 215-572-2900. E-mail: landbergt @ arcadia.edu

Accepted: 16 December 2014.

ISSN: Online 1696-3547, Print 0214-6282

(C) 2014 UBC Press

Printed in Spain 
confounded by genetic differences or a variety of environmental differences such as age, body size and condition. Naturally, yolk may be assumed to be a resource fueling growth and development, but testing hypotheses about the mechanisms underlying adaptive divergence is challenging because egg size covaries with so many other traits including evolved genetic and maternal effects, environmental differences and phenotypic plasticity (Bernardo 1996a; Kaplan 1998; Uller 2008). Allometric engineering, a type of controlled experimental phenotypic manipulation, addresses this by surgically isolating the effects of yolk quantity from potentially confounding variables allowing evaluation of the relative contributions of yolk provisioning vs. other effects (Bernardo 1991; Sinervo and Basolo 1996). This study experimentally addresses the question of the value of yolk from the perspectives of the mother and the offspring in terms of the relationship between the amount of yolk invested into an egg by the mother and the amount of phenotypic changes in the offspring.

The primary goal of this study was to examine which phenotypic differences respond to egg size variation and which evolved by other mechanisms by surgically reducing yolk reserves in embryos of two sister salamander species with divergent egg sizes and larval phenotypes. Relative to $A$. texanum, which maintains the ancestral breeding strategy of depositing many small eggs in ponds (Kraus and Petranka 1989), A. barbouri occupies streams and produces half as many eggs per clutch and each egg contains about twice as much yolk. These stream larvae hatch approximately two stages later, at larger body sizes, develop more rapidly and metamorphose earlier (Petranka 1982; Petranka and Sih 1987). Based on a previous study of a related species (Landberg 2014), surgical yolk removal was predicted to accelerate hatching (because yolk
TABLE 1

\section{REPEATED MEASURES MULTIVARIATE ANALYSIS OF VARIANCE FOR AMBYSTOMA TEXANUM AND A. BARBOURI HATCHING FROM DAY 11-21 ( $\mathrm{N}=167$ BOXES SAMPLED ON 4 DATES)}

\begin{tabular}{|c|c|c|c|c|c|}
\hline Subjects & Predictor & Test & $\mathrm{DF}^{1}$ & $F^{2}$ & Prob $>F^{3}$ \\
\hline Between & $\begin{array}{l}\text { Clutch[Species] } \\
\text { Species } \\
\text { Treatment } \\
\text { Species`Treatment }\end{array}$ & $\begin{array}{l}\text { F Test } \\
\text { F Test } \\
\text { F Test } \\
\text { F Test }\end{array}$ & $\begin{array}{l}16,143 \\
1,143 \\
3,143 \\
3,143\end{array}$ & $\begin{array}{l}113.7 \\
131.1 \\
0.99 \\
3.49\end{array}$ & $\begin{array}{c}<.0001 \\
<.0001 \\
0.40 \\
\mathbf{0 . 0 1 7 5}\end{array}$ \\
\hline Within & $\begin{array}{l}\text { Time } \\
\text { Time }{ }^{\star} \text { Clutch(Species) } \\
\text { Time }{ }^{\star} \text { Species } \\
\text { Time }{ }^{\star} \text { Treatment } \\
\text { Time }{ }^{\star} \text { Treatment }{ }^{\star} \text { Species }\end{array}$ & $\begin{array}{l}\text { F Test } \\
\text { Wilks' Lambda } \\
\text { F Test } \\
\text { Wilks' Lambda } \\
\text { Wilks' Lambda }\end{array}$ & $\begin{array}{l}3,141 \\
48,420 \\
3,141 \\
9,343 \\
9,343\end{array}$ & $\begin{array}{l}29.52 \\
2.44 \\
2.74 \\
0.40 \\
1.39\end{array}$ & $\begin{array}{c}<.0001 \\
<.0001 \\
\mathbf{0 . 0 4 5 9} \\
0.94 \\
0.19\end{array}$ \\
\hline
\end{tabular}

${ }^{1}$ Numerator, Denominator

${ }^{2}$ Exact $\mathrm{F}$ used in F-test and approximate $\mathrm{F}$ used in Wilks' Lambda

${ }^{3} \mathrm{P}$-values $<0.05$ are bolded

reserves will be depleted sooner), and reduce developmental rate, body size and survival in both species.

Additionally, this study was designed to test alternate hypotheses about the evolution of developmental plasticity in response to yolk variation with increased egg size in $A$. barbouri. Plasticity could stay the same, decrease or increase. If the response to egg size variation has not evolved, the null hypothesis is both species express similar plasticity to that of their relative, $A$. maculatum (which has intermediate egg size). If there is a single absolute lower threshold to the amount of yolk required to complete embryonic development (e.g. Smith and Fretwell 1974), the response is predicted to be more negative in $A$. texanum because their small eggs should be closer to this threshold. Removing similar amounts
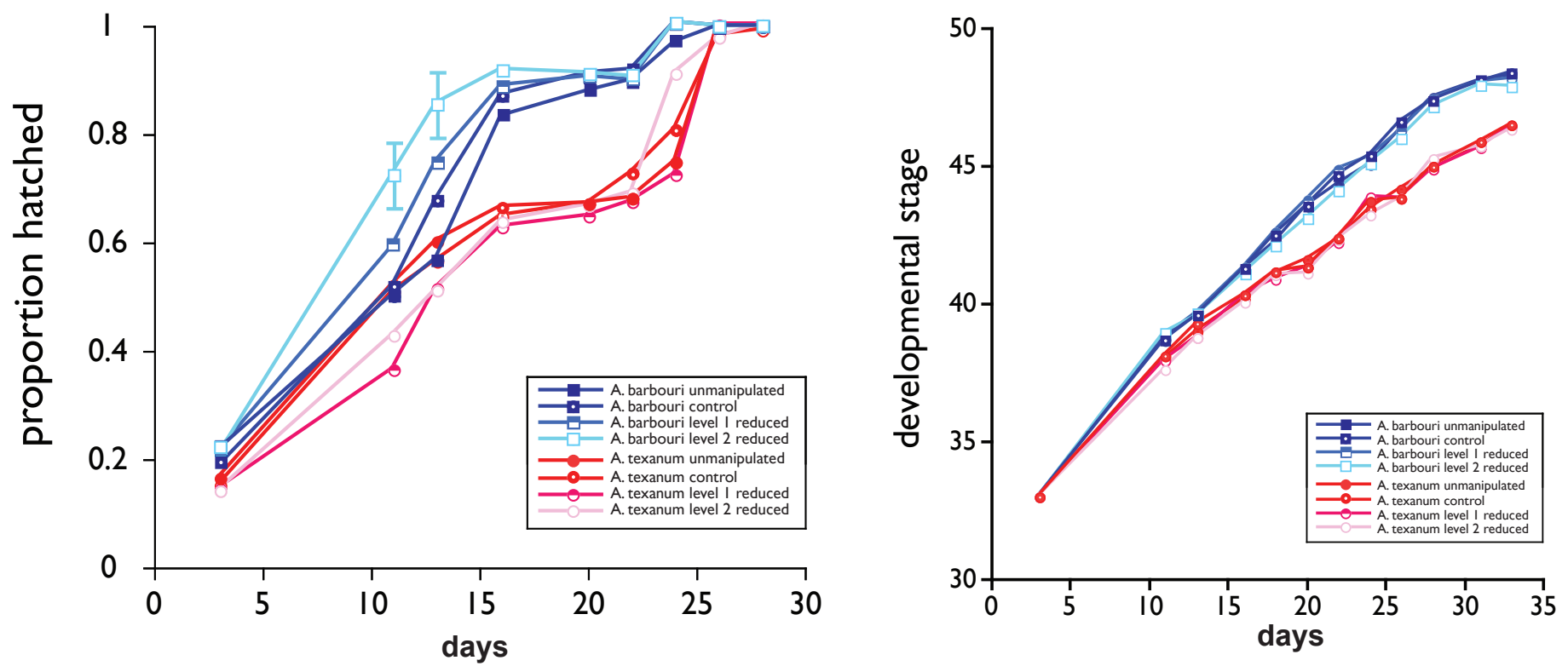

Fig. 1 (left). Hatching through time. ANOVA least squares treatment by species means for proportion of each tank hatched is shown adjusted for clutch effects (see Table 1 for results). The two species respond differently. Ambystoma barbouri hatches progressively earlier as more yolk is removed while A. texanum does not respond to yolk removal. Sample standard error bars are shown on the two individual sample dates where there are significant differences.

Fig. 2 (right). Development through time. Harrison stage (ANOVA least squares treatment mean adjusted for clutch effects) is shown (symbols larger than s.e.; see Table 2 for results). There is a significant treatment effect across both species, but no species by treatment interaction. The $2 x$ reduced larvae of both species tend to be the least developed relative to the controls. Note that the effect of yolk removal is small relative to fixed species differences. 
REPEATED MEASURES MULTIVARIATE ANALYSIS OF VARIANCE FOR AMBYSTOMA TEXANUM AND A. BARBOURI DEVELOPMENTAL STAGE THROUGH DAY 31 (N=145 BOXES SAMPLED ON 5 DATES)

\begin{tabular}{|c|c|c|c|c|c|}
\hline Subjects & Predictor & Test & $\mathrm{DF}^{1}$ & $F^{2}$ & Prob $>F^{3}$ \\
\hline Between & $\begin{array}{l}\text { Clutch[Species] } \\
\text { Species } \\
\text { Treatment } \\
\text { Species*Treatment }\end{array}$ & $\begin{array}{l}\text { F Test } \\
\text { F Test } \\
\text { F Test } \\
\text { F Test }\end{array}$ & $\begin{array}{l}16,121 \\
1,121 \\
3,121 \\
3,121\end{array}$ & $\begin{array}{c}43.09 \\
450.95 \\
4.09 \\
1.03\end{array}$ & $\begin{array}{c}<.0001 \\
<.0001 \\
0.0083 \\
0.38\end{array}$ \\
\hline Within & $\begin{array}{l}\text { Time } \\
\text { Time }{ }^{\star} \text { Clutch(Species) } \\
\text { Time }{ }^{\star} \text { Species } \\
\text { Time }{ }^{\star} \text { Treatment } \\
\text { Time }{ }^{\star} \text { Treatment }{ }^{\star} \text { Species }\end{array}$ & $\begin{array}{l}\text { F Test } \\
\text { Wilks' Lambda } \\
\text { F Test } \\
\text { Wilks' Lambda } \\
\text { Wilks' Lambda }\end{array}$ & $\begin{array}{c}4,118 \\
64,464 \\
4,118 \\
12,312 \\
12,312\end{array}$ & $\begin{array}{c}2453.13 \\
7.24 \\
30.10 \\
1.48 \\
1.45\end{array}$ & $\begin{array}{c}<.0001 \\
<.0001 \\
0.0459 \\
0.13 \\
0.14\end{array}$ \\
\hline
\end{tabular}

${ }^{1}$ Numerator, Denominator

${ }^{2}$ Exact $\mathrm{F}$ used in $\mathrm{F}$-test and approximate $\mathrm{F}$ used in Wilks' Lambda

${ }^{3} \mathrm{P}$-values $<0.05$ are bolded

of yolk from $A$. barbouri should then have less of an effect because their large eggs far exceed such a threshold (and increases in egg size are expected to give diminishing fitness returns). Studies of plants (Grime 1979) and a previous study of the responses of $A$. barbouri and $A$. texanum to oxygen (Landberg 2010) suggest that low-resource environments select for phenotypes that are stress tolerant and have low magnitudes of plasticity whereas high-resource environments select for phenotypes that have the ability to take advantage of resources and have high plasticity. Empirical support for an increase in phenotypic plasticity with egg size comes from both within and between species (McAlister 2007; Michimae et al., 2009). If high maternal investment in yolk has acted as a high-resource selective environment, phenotypic plasticity is expected to increase in $A$. barbouri.

\section{Results}

Hatching was significantly affected by clutch, species, and species*treatment interaction (Table 1; Fig. 1). As predicted, yolk removal resulted in earlier hatching, but the significant species*treatment interaction indicated that the effect of yolk removal differed between species. Tukey post-hoc tests confirm that Ambystoma barbouri responded to yolk reduction by hatching earlier, but $A$. texanum did not. The time courses of hatching also differed significantly between the species (time*species interaction).

Developmental stage was affected by clutch, species and treatment but not species*treatment interaction (Table 2, Fig. 2). On most sample dates, the $2 x$ reduced treatment had the lowest

TABLE 4

\section{ANALYSIS OF COVARIANCE OF AVERAGE SNOUT-VENT AND TAIL LENGTHS FOR EACH TANK MEASURED ON DAY $63(\mathrm{~N}=97)$}

\begin{tabular}{llccc} 
Response & Predictor & DF & F Ratio & Prob $>F^{\mathbf{1}}$ \\
\hline Snout-vent length & density & 1 & 5.7888 & $\mathbf{0 . 0 1 8 6}$ \\
& Clutch[Species] & 12 & 6.6979 & $<.0001$ \\
& Species & 1 & 14.5980 & $\mathbf{0 . 0 0 0 3}$ \\
& Treatment & 3 & 4.2588 & $\mathbf{0 . 0 0 7 8}$ \\
Tail length & Species ${ }^{*}$ Treatment & 3 & 4.5908 & $\mathbf{0 . 0 0 5 2}$ \\
& density & 1 & 21.5698 & $<.0001$ \\
& Clutch[Species] & 12 & 5.9763 & $<.0001$ \\
& Species & 1 & 0.1378 & 0.7115 \\
& Treatment & 3 & 3.3974 & $\mathbf{0 . 0 2 2 0}$ \\
& Species*Treatment & 3 & 4.4839 & $\mathbf{0 . 0 0 5 9}$ \\
\hline
\end{tabular}

$p$-values $<0.05$ are bolded

\section{REPEATED MEASURES MULTIVARIATE ANALYSIS OF VARIANCE FOR AMBYSTOMA TEXANUM AND A. BARBOURI SURVIVAL THROUGH DAY 31 ( $\mathrm{N}=177$ BOXES SAMPLED ON 5 DATES)}

\begin{tabular}{|c|c|c|c|c|c|}
\hline Subjects & Predictor & Test & DF & F statistic ${ }^{1}$ & Prob $>F^{2}$ \\
\hline Between & $\begin{array}{l}\text { Clutch[Species] } \\
\text { Species } \\
\text { Treatment } \\
\text { Species*Treatment }\end{array}$ & $\begin{array}{l}\text { F Test } \\
\text { F Test } \\
\text { F Test } \\
\text { F Test }\end{array}$ & $\begin{array}{c}16 \\
1 \\
3 \\
3\end{array}$ & $\begin{array}{l}7.16 \\
8.21 \\
8.93 \\
3.09\end{array}$ & $\begin{array}{l}<.0001 \\
0.0047 \\
<.0001 \\
0.0289\end{array}$ \\
\hline Within & $\begin{array}{l}\text { Time } \\
\text { Time*Clutch(Species) } \\
\text { Time* Species } \\
\text { Time }{ }^{\star} \text { Treatment } \\
\text { Time }{ }^{\star} \text { Treatment }{ }^{\star} \text { Species }\end{array}$ & $\begin{array}{l}\text { F Test } \\
\text { Wilks' Lambda } \\
\text { F Test } \\
\text { Wilks' Lambda } \\
\text { Wilks' Lambda }\end{array}$ & $\begin{array}{c}4 \\
64 \\
4 \\
12 \\
12\end{array}$ & $\begin{array}{l}68.66 \\
2.09 \\
4.18 \\
0.94 \\
1.42\end{array}$ & $\begin{array}{c}<.0001 \\
<.0001 \\
0.0031 \\
0.51 \\
0.15\end{array}$ \\
\hline
\end{tabular}

${ }^{1}$ Exact $\mathrm{F}$ used in F-test and approximate $\mathrm{F}$ used in Wilks' Lambda

${ }^{2} \mathrm{P}$-values $<0.05$ are bolded

average Harrison developmental stage among Ambystoma barbouri treatments; the $2 x$ reduced treatment was also often the least developed among the $A$. texanum treatments. The fixed species differences were large relative to the treatment effects and the significant species*time interaction indicates that the difference between the species increased over time because $A$. barbouri had a higher developmental rate.

Survival was significantly affected by clutch, species, treatment and species*treatment interaction (Table 3, Fig. 3). A. barbouri and $A$. texanum controls had similarly high survival. However, the unmanipulated $A$. barbouri had lower survival than the controls. Both species responded to yolk removal and survival decreased with the amount of yolk removed, however $A$. barbouri responded much more to yolk removal than $A$. texanum. Survival dropped dramatically on day 31 because an equipment malfunction caused

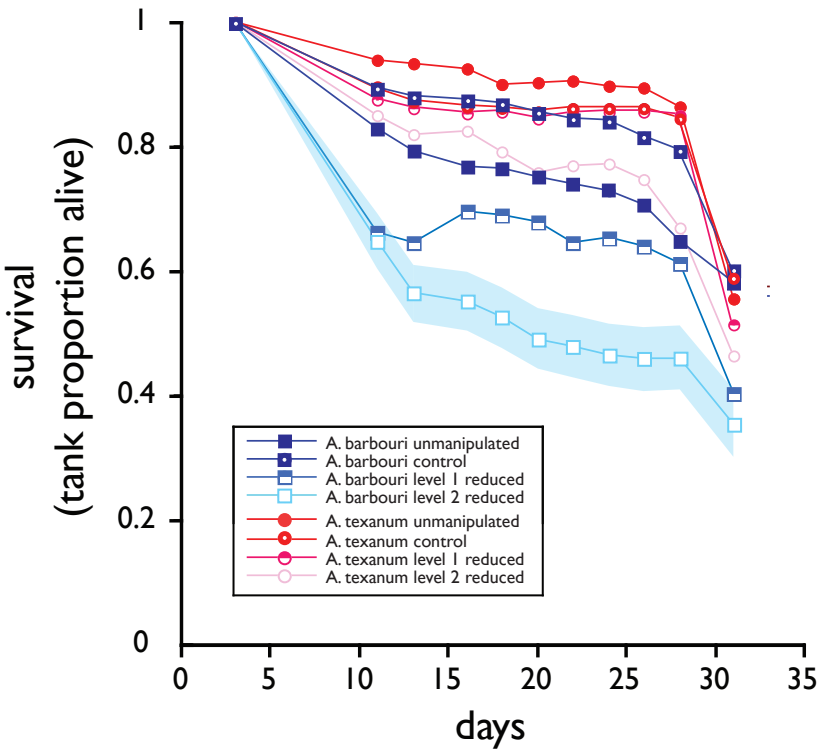

Fig. 3. Survival through time. ANOVA least squares treatment means adjusted for clutch effects are shown (see Table 3 for results). There were significant treatment and treatment by species interaction indicating the response occurred in both species, but the magnitude of response was greater in A. barbouri. Standard errors are shown as a shaded region around the A. barbouri $2 x$ reduced treatment; s.e. were similar in other treatments but not shown to avoid clutter. Survival appears to increase occasionally from model adjustment error. 


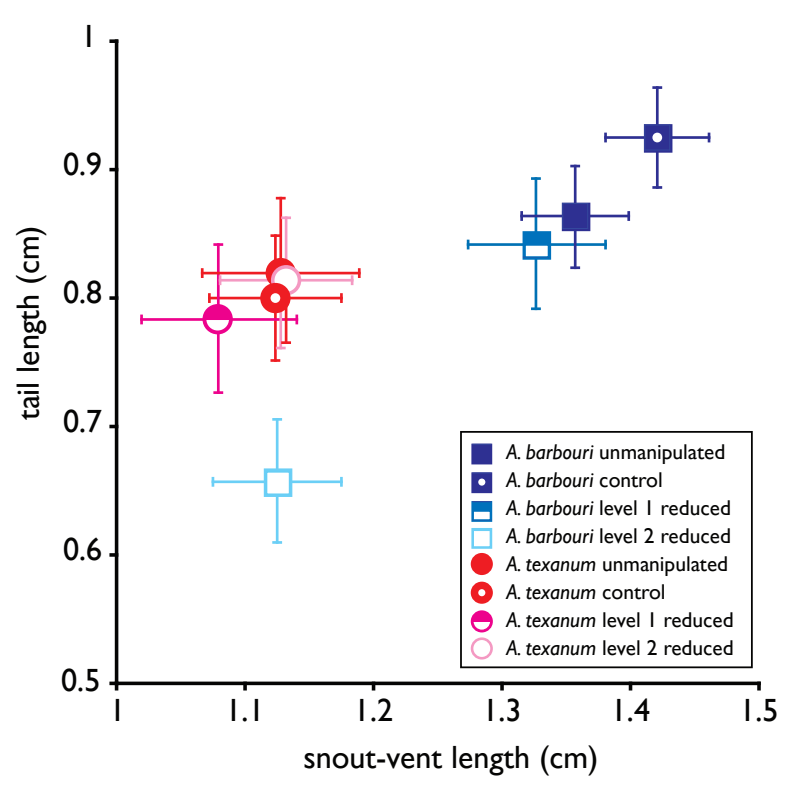

Fig. 4. Body size (see Table 4 for results). ANOVA least squares adjusted treatment means ( \pm s.e.) for snout-vent length (on the $x$-axis) and tail length (on the $y$-axis) on day 63. A. barbouri responded strongly in both traits to yolk removal while A. texanum did not respond resulting in significant treatment by species effects in both traits.

room temperature to rise to over $30^{\circ} \mathrm{C}$ which caused high mortality.

Snout-vent length on day 63 was significantly affected by clutch, species, treatment, and species ${ }^{*}$ treatmentinteraction (Table 4, Fig. 4). Tukey post-hoc test reveals that none of the $A$. texanum treatment groups differed. Among $A$. barbouri however, the $2 x$ reduced group was smaller than both the unmanipulated and the control groups. The $1 \mathrm{x}$ reduced group was intermediate and not different from other groups. Tail length on day 63 was similarly affected by clutch, treatment, and species ${ }^{\star}$ treatment interaction, but did not differ significantly between species (Table 4, Fig. 4). Tukey post-hoc tests revealed that none of the $A$. texanum treatment groups were different from each other but among $A$. barbouri treatments, the $2 x$ reduced group had smaller tail length than both the unmanipulated and the control groups. The $1 \mathrm{x}$ reduced group was intermediate and not significantly different from the other groups.

\section{Discussion}

\section{Evaluation of surgical technique}

The simple yolk removal technique employed here was highly successful and minimally invasive (with $\sim 90 \%$ initial survival). While this technique includes variation in yolk removal that could lead to different quantity of yolk substances (lipids, proteins and hormones) being removed, the very large sample size of this experiment $(>1000$ individuals), facilitated by its simplicity and ease, helps overcome these potential difficulties. Future advancements of the technique should consider analysis of removed yolk. Splitting whole eggs along cleavage planes (pioneered by Hans Spemann) could also be used to study egg size directly as opposed to embryonic yolk reserves. Furthermore, this yolk removal experiment best tests how $A$. barbouri responds to having maternal investment closer to ancestral $A$. texanum levels but not the reciprocal question of how $A$. texanum responds to having maternal investment closer to A. barbouri levels. It is likely that yolk addition would, for example, delay hatching in A. texanum, but new techniques must be developed to test this hypothesis.

The unmanipulated and surgical sham-operated control groups revealed that the surgery itself (not yolk removal) can increase growth and viability. In this study, $A$. barbouri body size and survival were both increased in the surgical control compared to the unmanipulated groups. This counterintuitive result does not appear to be an artifact since similar results were found in other studies using the same technique (Landberg, 2014 and unpublished results). Ambystoma maculatum also showed a positive response to the surgery in terms of increased developmental stage and body size metrics. This suggests that the surgery does not induce direct adverse effects in the embryos, but stress associated with surgery may activate pathways that facilitate resource usage in response to perceived environmental threats such as egg or larval predators (mimicked by the surgery).

\section{Hatching}

Yolk removal increased the proportion hatched in $A$. barbouriby about $20 \%$ in the $2 x$ reduced group relative to the sham control on days 11 and 13 (Fig. 1). The response appeared linear since the $1 x$ reduced group was intermediate between the $2 x$ and the control that had no yolk removed. The early hatching response suggests that yolk levels are monitored and embryos hatch as reserves run low and they must transition to exogenous feeding. This response was also seen in $A$. maculatum (which has intermediate egg size; Landberg 2014) and is consistent with the correlation between increasing egg size and later hatching times across salamander species. Evolutionary lability in this trait may have led to a lack of a response in $A$. texanum with their very small egg sizes and the large response by $A$. barbouriappears to be a re-evolved capacity.

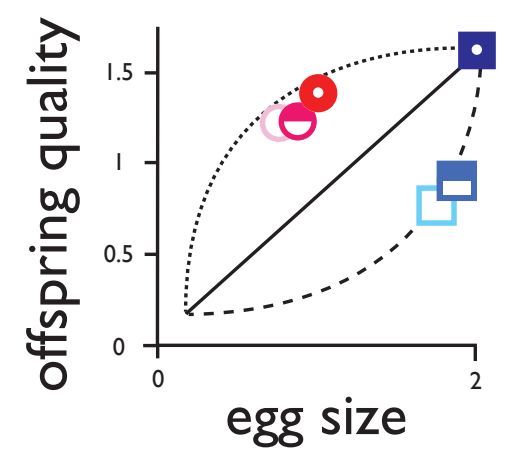

Fig. 5. The value of yolk. Relative offspring quality (survival times total length) is a metric of phenotypic quality in a common garden lab environment as proxy for offspring fitness in nature. A. barbouri controls have egg size set to twice the size of A. texanum controls and yolk removal treatments are shown as reducing egg size by $12.5 \%$ and $25 \%$ for the $1 x$ and $2 x$ yolk reduction treatments respectively (symbols as in previous graphs). The dotted line shows an egg size/fitness function like the diminishing returns optimal egg size model of Smith and Fretwell (1974). The solid line shows relative offspring quality increasing at a constant rate. The dashed line shows it increasing exponentially with egg size. The data presented here do not fit any simple model because minimum egg size thresholds and developmental plasticity in response to yolk variation evolve. 
In the wild, Ambystoma barbouri hatches approximately two stages later than $A$. texanum (Petranka 1982). At the peak of hatching (when $50 \%$ of each treatment has hatched), the difference between the $A$. barbouri $2 x$ reduced and the control treatments is about 2 to 3 days, corresponding to an average developmental stage increase of approximately one Harrison stage. The effect of $\sim 25 \%$ yolk removal therefore accounts for about half of the difference between species in stage at hatching.

\section{Developmental rate}

While yolk removal consistently reduced developmental stage in $A$. barbouri, this effect did not appear as consistently in $A$. texanum (Table 2; Fig. 2). However, the species ${ }^{*}$ treatment interaction was not significant suggesting that both species had similar small magnitude responses throughout the study. The time*treatment interaction was not significant indicating there may have been a small bias in the staging (where the small yolk-reduced animals appear underdeveloped) rather than a reduction of developmental rate per se. Nevertheless, treatment effects were small relative to the fixed difference in developmental rate between species. Rapid development has been regarded as an adaption to avoiding desiccation caused by the highly ephemeral streams $A$. barbouri occupies (Petranka and Sih 1987). While it seems intuitive that large egg size and yolk reserves could facilitate rapid development, and it has been shown to be correlated in other species (Kaplan 1985; Bradford 1990), it does not appear that the doubling of egg size in $A$. barbouri accounts for the majority of difference in developmental rate between the sister species. This study supports the previous study (Petranka et al., 1987) that found no evidence of within-species correlations between egg size and developmental rate and concluded that fixed genetic and metabolic effects accounted for the difference. It seems that intrinsic developmental rate of $A$. barbouri has increased much more than the small effect that yolk has on developmental rate.

\section{Survival}

Survival of both species was lower in the yolk-reduced treatments which strongly suggests that yolk acts as a resource and increases the viability of embryos and larvae. Ambystoma barbouri had lower survival than $A$. texanum across all treatments but also a larger magnitude response to yolk removal (Fig. 3). The difference between the control and the $2 x$ reduced group in $A$. texanum was only about $10 \%$ while the difference between those same groups (with similar relative amounts of yolk removed) in A. barbouri was close to $40 \%$. Even if similar absolute magnitudes of yolk removal are compared (between $1 \mathrm{x}$ reduced $A$. barbouri and $2 x$ reduced $A$. texanum), $A$. barbouri had twice as much mortality as $A$. texanum ( $\sim 20 \%$ vs. $\sim 10 \%$ respectively). These results provide experimental evidence that with an increase in egg size, $A$. barbourihas evolved greater reliance on yolk reserves for viability.

\section{Body size}

Both snout-vent and tail lengths decreased significantly when yolk was removed in A. barbouri but not in A. texanum (Fig. 4). The effect size was large in $A$. barbouri- $\sim 3 \mathrm{~mm}$ reduction in snout-vent length between the control and $2 x$ reduction groups. This provides further evidence that $A$. barbouri has evolved an increased response to yolk variation. These results represent longterm effects, since these measurements were made two months after the beginning of the experiment. They are also robust to the effects of density which were accounted for in the ANOVA model and the effects of high levels of temperature-induced mortality that occurred unexpectedly on day 31. Rather than artifactually causing the effect seen here, this unplanned mortality event may have reduced the initial body size effects of yolk removal since the smallest and weakest animals would be the most likely to die under heat stress. Thus, this makes the experiment more conservative and underscores the biological significance of such a large and robust effect size. The current results suggest that the effect of increased egg size may cascade from embryos to hatchlings and throughout the larval period. Larger snout-vent length throughout the larval period may also allow $A$. barbouri to compete better and metamorphose earlier under stressful conditions than if they had smaller eggs (e.g. Einum and Fleming 1999; Allen et al., 2008; but see Moore et al., in press).

\section{Trait integration, evolution of plasticity, and the value of yolk}

Yolk removal significantly affected Ambystoma barbourihatching time, survival and body size. These results provide experimental support for the hypothesis that maternal investment in yolk reserves (and egg size) acts as an integrator of complex phenotypic variation by affecting multiple aspects of the salamander larval phenotype. Yolk removal affected a suite of traits in $A$. barbouri, but surprisingly these effects are not universal as $A$. texanum had hardly any response in most traits. Relative to the outgroup, $A$. maculatum, (Landberg 2014), A. texanum (with small eggs) has canalized hatching and body size variation while $A$. barbouri (with large eggs) integrates them into its responses to yolk removal (as does $A$. maculatum with intermediate egg size). These data support the hypothesis that phenotypic plasticity in response to egg size variation increased in $A$. barbouri with its derived evolutionary increase in egg size. This suggests that as mothers invest more yolk in each egg, the offspring experience a high-resource environment that selects for the ability to use and reliance on yolk. Conversely, the low-resource environments experienced by embryos of small-egged species create selection favoring robustness, stress tolerance and low amounts of phenotypic plasticity (Grime 1979). These data support the hypothesis that large eggs evolved in part because they induce both larger body size and an adaptive plastic hatching delay to a later developmental stage that reduces stream drift and predation by flatworms (Petranka et al., 1987).

Recent studies have shown there can be strong maternal effects of egg size on offspring plasticity. Offspring from larger cockroach, echinoid, salamander and frog eggs have higher phenotypic plasticity (Doughty 2002, Holbrook and Schal 2004; McAlister 2007; Michimae et al., 2009; Martin and Pfennig, 2010). This study suggests that with evolutionary egg size increases, more traits are added to the suite of traits responding to egg size variation and the response of each trait to yolk quantity variation increases. Therefore, as egg size increases, the phenotypic value of yolk increases for both mothers and offspring because small differences in yolk allocation have increased effects on relative offspring quality (Fig. 5). This suggests that because embryos coevolve increased trait integration and plasticity, the phenotypic value of yolk in life history theory models (e.g. Smith and Fretwell 1974; van Noordwijk and de Jong 1986; Winkler and Wallin 1987; Hendry et al., 2001; Roff 2002) should also increase with egg size. The Smith and Fretwell (1974) model has been criticized for assuming the 
egg size/progeny fitness function has a threshold and is a convex monotonically increasing function with an asymptote (Bernardo 1996b; Hendry et al., 2001). This diminishing returns model means that yolk loses value as egg size increases. No simple function fits the Ambystoma egg size/fitness relationship because minimum egg size thresholds and plasticity to egg size have evolved. At reduced (but still relatively large) egg sizes, $A$. barbouri has lower relative offspring quality than $A$. texanum (Fig. 5). To model the egg size/offspring fitness function we should include the evolution of thresholds and developmental plasticity of mothers (Kaplan 1998; Hendry et al., 2001). Additionally, we need functions for the evolving relationship between egg size and a suite of offspring trait phenotypes and their performance and fitness consequences in different environments (Arnold 1983; Kaplan and Phillips 2006). This study provides experimental evidence that increased maternal provisioning levels coevolve with increased offspring trait plasticity and increased integration of traits.

\section{Materials and Methods}

\section{Animal husbandry}

A common garden design was used to separate environmental differences induced by pond and stream habitats from fixed and plastic species differences. Ambystoma texanum egg masses $(n=9)$ were collected in a vernal oxbow pond in Beaver Dam, Kentucky on March 8, 2008 and $A$. barbouriegg clutches adhering under rocks $(n=9)$ were collected on March 9, 2008 in an ephemeral stream, Raven Run, in Lexington, Kentucky. Clutches were kept in water-filled plastic bags and chilled $\left(\sim 5^{\circ} \mathrm{C}\right)$ in a cooler during transport to Connecticut. Collections were made in accordance with Kentucky law and animals were housed according to University of Connecticut guidelines.

The unit of replication throughout the study was a small stackable custombuilt acrylic tank $(10 \times 10 \times 6 \mathrm{~cm})$ filled $\sim 4 \mathrm{~cm}$ deep with distilled water that was re-ionized with $\sim 0.15 \mathrm{~g} /$ liter Instant Ocean sea salt mixture (changed weekly or as necessary). Tanks were stacked up to eight high, four stacks deep and up to eight rows across a lab bench in an air-conditioned room with a 14:10 light:dark cycle. Temperature of the tanks varied a few degrees across the bench and increased slightly through the experiment (range $15-20^{\circ} \mathrm{C}$ ). Tanks were redistributed haphazardly among stacks and rows every few days to distribute any bias created from spatial heterogeneity. Live invertebrate prey were collected in aquatic vegetation from a local fish hatchery. This diverse food source was primarily blood worms, but also included a large quantity of midge larvae. Feedings occurred weekly (or more frequently), with the quantities varying through the season (range $1-4 \mathrm{ml}$ ), but always divided evenly among the tanks. Sadly, electrical fires on days 31 and 66 caused air conditioning failure, high temperature, mortality and termination of the experiment prior to metamorphosis.

\section{Allometric engineering}

Yolk was surgically removed from embryos to experimentally reduce maternal investment in yolk reserves (performed at Harrison stages 26-35; Harrison 1969). A split-clutch design was used to account for maternal genetic differences within species. Each haphazardly selected embryo within a clutch was assigned to a different treatment group until each replicate tank had six animals or the clutch ran out of eggs.

The four treatment groups were as follows: Unmanipulated (egg capsule pierced and embryo repositioned with light suction but without poking or yolk removal); Control (needle poked through the egg capsule, abdomen and was moved around to mimic disturbance associated with yolk removal but no yolk was removed); Level 1 reduced (1x; same as control but with yolk removal as detailed below; Level 2 reduced ( $2 x$; removal of twice the volume of yolk as a $1 \mathrm{x}$ reduction from a single surgical site).

The exact quantity of yolk removed from each individual was not mea- sured precisely because each needle was custom-made, yolk often mixed with water as it was removed from the embryo and yolk is too viscous to be expelled from the needle. Several estimates were made using a calibration tip for a micropipette and experience with over two thousand previous surgeries helped ensure consistency of the procedure. Ambystoma barbouri has eggs that are approximately twice as big as $A$. texanum, so $A$. barbouri treatment groups had twice as much yolk removed. The $1 \mathrm{x}$ reduced treatment group had $\sim 10-15 \%$ of the yolk reserves removed - Ambystoma barbouri had $\sim 4 \mu$ l removed while $A$. texanum had $\sim 2 \mu$ l removed. The $2 x$ reduced group had $\sim 25 \%$ of the yolk reserves removed- $A$. barbouri had $\sim 8 \mu$ l removed while $A$. texanum had $\sim 4 \mu$ l removed.

Surgeries were performed with glass needles fashioned by heating Pasteur pipettes over a Bunsen burner flame. Once softened, the end of the pipette was pulled until it broke. The thin tapering tip was then ground down at $\sim 45$ degree angle on 600 grit and then 1500 grit sandpaper. This created an oval syringe-like profile on the tip of the needle (diameter $0.025 \pm 0.005$ $\mathrm{cm}$ ). The internal diameter of the needles varied since they were hand pulled. Needles were reused until they broke, dulled or became clogged.

Yolk reduction surgeries were performed under a dissecting microscope at low power $(\sim 30 \mathrm{x})$. Yolk was drawn into the glass needle with suction via a short length of rubber tubing. A micromanipulator was used to precisely maneuver the needle in three dimensions. An egg capsule containing an embryo was removed from its jelly matrix and placed in the dimple formed on top of a $2 \mathrm{~cm}$ cube of cooled wax. The needle was advanced, (tip down, ground surface vertical) from above and the right ( 45 degree angle) until it pierced the egg capsule. A ventro-lateral site on one side of the abdomen of each embryo was targeted for the surgical site. The ectoderm overlying the yolk was pierced with the needle and light suction was applied once the tip was embedded in yolk. A small quantity of yolk was drawn up into the needle, which was then withdrawn, and the embryo (still in the egg capsule) was transferred to chilled water.

\section{Data \& analysis}

The first day of surgeries was designated as day zero of the experiment. Surgeries were performed over the course of a week (March 10-16, 2008) and data from this period are plotted on day 3.5. Approximately six eggs of the same treatment and clutch were in each tank to start with $(5.9 \pm 0.8$ individuals/tank, mean \pm s.d.; $n=177$ tanks). Once the surgeries were complete, tanks were censused every two or three days for the number of living animals, number of animals hatched and their developmental stages using Harrison (1969) and Brown-Wilusz (2008). Proportions of living animals hatched and of original animals surviving were arcsine square-root transformed prior to analysis to match the assumptions of error distributions. To account for the non-independence of subsequent sample dates and capture time-dependent interactions, each of these metrics was analyzed with a multivariate analysis of variance using a repeated measures design (Jmp version 5) with clutch (within species), species and treatment as class variables. The repeated measures design allows estimation of timedependent effects while accounting for the non-independence of samples within a replicate through time. Hatching occurred over approximately 3 weeks, but only the middle 10 days (four sample dates) of the hatching period were analyzed because the variance is zero at the beginning and end of the hatching period (because all individuals start unhatched and end up hatched). Survival (proportion of original population alive) and developmental stage were analyzed using 5 evenly spaced sample dates covering the period between days 11 and 31 (more sample dates shown in figures). Snout-vent and tail length of a random individual in each tank $(n=97)$ were measured from high resolution lateral view digital photographs taken on day 63 . Each image had a $2 \mathrm{~cm}$ scale bar visible that was used to calibrate the images before they were analyzed using Image 64 software. Snout-vent and tail lengths were analyzed separately using ANCOVA with clutch, species and treatments as factors. As in the other metrics, the species by treatment interaction was included because it permits examination of the evolution of phenotypic plasticity (i.e. species respond differently to yolk variation). Additionally, density (number of animals in each tank) was 
used as a covariate because mortality decreased density and competition in some tanks. The species*treatment least squared means from the ANCOVAs were used in Tukey post-hoc tests to test for differences between specific groups at the 0.05 confidence level.

To illustrate the phenotypic quality of offspring in the lab (as a proxy for natural environmentally-dependent fitness) I used ANOVA adjusted species*treatment means to create a variable, 'relative offspring quality', calculated as survival times total length (snout-vent length + tail length; data from above, day 31 for survival and day 63 for total length). For graphing, $A$. barbouri control treatment egg size was set to twice the size of $A$. texanum controls and yolk removal treatments were plotted as reducing egg size by $12.5 \%$ and $25 \%$ for the $1 \mathrm{x}$ and $2 \mathrm{x}$ yolk reduction treatments respectively.

\section{Acknowledgements}

This research, which was supported by the Connecticut Museum of Natural History Wetzel Fund and NSF Doctoral Dissertation Improvement Grant number 0808300, approved by the University of Connecticut IACUC and done in accordance with the laws of Kentucky. Thanks to my committee for comments on previous drafts, John Niedzwiecki for generous field help and advice and to Jim Petranka for his previous work describing these species and encouragement. Thanks to Raven Run for help and access to the preserve and to Watershed Studies Institute and Hancock Biological Station for support during the preparation of this MS.

\section{References}

ALLEN, J. D. (2012) Effects of egg size reduction on development time and juvenile size in three species of echinoid echinoderms: implications for life history theory. J. Exp. Marine. Biol. Ecol. 422-423: 72-80.

ALLEN, R. M., BUCKLEY Y. M., MARSHALL D. J. (2008) Offspring size plasticity in response to intraspecific competition: an adaptive maternal effect across life history stages. Am Nat. 171: 225-237.

ARNOLD, S. J. (1983) Morphology, performance and fitness. Am. Zool. 23: 347-334.

BERNARDO, J. (1991) Manipulating egg size to study maternal effects on offspring traits. Trends Ecol. Evol. 6: 1-2.

BERNARDO, J. (1996a) Maternal effects in animal ecology. Am. Zool. 36: 83-105

BERNARDO, J. (1996b) The particular maternal effect of propagule size, especially egg size: Patterns, models, quality of evidence and interpretations. Am. Zool. 36: $216-236$.

BRADFORD, D. F. (1990) Incubation time and rate of embryonic development in amphibians: The influence of ovum size, temperature, and reproductive mode. Physiol. Zool. 63: 1157-80.

BROWN-WILUSZ, L. (2008) Ontogenetic effects of hatching plasticity in the spotted salamander (Ambystoma maculatum) due to egg and larval predators. Univ. Connecticut Honors Scholar Theses. Paper 53. http://digitalcommons.uconn. edu/srhonors_theses/53

DOUGHTY, P. (2002) Coevolution of developmental plasticity and large egg size in Crinia georgiana. Copeia 2002: 928-937.

DUELLMAN, W. E., and TRUEB, L. (1986) Biology of amphibians. John Hopkins University Press, Baltimore, MD, USA.

EASTMAN, J. M., NIEDZWIECKI, J. H., NADLER, B. P., and Storfer, A. (2009) Duration and consistency of historical selection are correlated with adaptive trait evolution in the streamside salamander, Ambystoma barbouri. Evolution 63: 2636-2646

EINUM, S. and FLEMING I. A. (1999) Maternal effects of egg size in brown trout (Salmo trutta): norms of reaction to environmental quality. Proc. R. Soc. Lond. B. 266: 2095-2100.

GRIME, J. P. (1979) Plant Strategies and Vegetation Processes. 222 pp., John Wiley, New York.

HARRISON, R. G. (1969) Harrison stages and description of the normal development of the spotted salamander, Amblystoma punctatum (Linn.). In: Organization and development of the embryo (S. Wilens, Ed.). New Haven and London, Yale University Press. 290.

HENDRY, A. P., DAY, T., and COOPER, A. B. (2001) Optimal size and number of propagules: allowance for discrete stages and effects of maternal size on repro- ductive output and offspring fitness. Am. Nat. 157: 387-407.

HOLBROOK, G. L. and SCHAL, C. (2004) Maternal investment affects offspring phenotypic plasticity in a viviparous cockroach. Proc. Nat. Acad. Sci. USA 101: 5595-5597.

KAPLAN, R. H. (1980) The implications of ovum size variability for offspring fitness and clutch size within several populations of salamanders (Ambystoma). Evolution 34: 51-64.

KAPLAN, R. H. (1985) Maternal influences on offspring development in the California newt, Taricha torosa. Copeia 1985: 1028-1035.

KAPLAN, R. H. (1998) Maternal effects, developmental plasticity, and life history evolution: an amphibian model. Pp. 244-260 in TA Mousseau and CW Fox eds. Maternal effects as adaptations. Oxford University Press. New York.

KAPLAN, R. H. and COOPER W. S. 1984. The evolution of developmental plasticity in reproductive characteristics: An application of the "adaptive coin-flipping" principle. Am. Nat. 123: 393.

KAPLAN, R. H. and PHILLIPS, P. C. (2006) Ecological and developmental context of natural selection: maternal effects and thermally induced plasticity in the frog Bombina orientalis. Evolution 60: 142-156.

KAPLAN, R. H., and SALTHE, S. N. (1979) The allometry of reproduction: an empirical view in salamanders. Am. Nat. 113: 671-689.

KRAUS, F., and PETRANKA, J. W. (1989) A new sibling species of Ambystoma from the Ohio River drainage. Copeia 1989: 94-110.

LANCASTER, L. T., MCADAM, A. G., SINERVO, B. G. (2010) Maternal adjustment of egg size organizes alternative escape behaviors, promoting adaptive phenotypic integration. Evolution 64: 1607-1621.

LANDBERG, T. (2014) Embryonic yolk removal affects a suite of hatchling salamander traits. J. Exp. Zool. B: Molec. Dev. Evol. 322: 45-53.

LANDBERG, T. (2010) Evolution of developmental plasticity in ambystomatid salamanders. Doctoral dissertation, University of Connecticut. http://digitalcommons. uconn.edu/dissertations/AAI3415549/

MARTIN, R. A, PFENNIG, D. W. (2010) Maternal investment influences expression of resource polymorphism in amphibian: implications for the evolution of novel resource-use phenotypes. PLOS One 5:e9117

MCALISTER, J. S. (2007) Egg size and the evolution of phenotypic plasticity in larvae of the echinoid genus Strongylocentrotus. J. Exp. Mar. Biol. Ecol. 352: 306-316.

MICHIMAE, H., NISHIMURA, K., TAMORI, Y., WAKAHARA, M. (2009) Maternal effects on phenotypic plasticity in larvae of the salamander Hynobius retardatus. Oecologia 160: 601-608.

MOORE, M. P., LANDBERG, T. and WHITEMAN, H. H. (in press) Maternal investment mediates life history variation with context-dependent fitness consequences. Ecology. DOI: 10.1890/14-1602.1

NUSSBAUM, R. A. (2003) Parental care. In: Reproductive biology and phylogeny of Urodela. Sever DM, editor. 1st ed. Science Publishers. 529 p.

PETRANKA, J. W. (1982) Geographic variation in the mode of reproduction and larval characteristics of the small-mouthed salamander in the east-central United States. Herpetologica 38: 252-262.

PETRANKA J.W. (1984) Sources of interpopulation variation in growth responses of larval salamanders. Ecology 65: 1857-1865

PETRANKA, J. W. (1998) Salamanders of the United States and Canada. Smithsonian Institution Press, Washington, DC.

PETRANKA, J. W., and SIH, A. (1987) Habitat duration, length of larval period, and the evolution of a complex life cycle of a salamander, Ambystoma texanum. Evolution 41: 1347-1356

PETRANKA, J. W., SIH, A, KATS, L. B. and HOLOMUZKI, J.R. (1987) Stream drift, size-specific predation, and the evolution of ovum size in an amphibian. Oecologia 71: 624-630.

ROBERTSON, A. V., RAMSDEN, C., NIEDZWIEKI, J., FU, J., BOGART, J. P. (2006) An unexpected recent ancestor of unisexual Ambystoma. Mol. Ecol. 15:3339-3351.

ROFF, D. A. (2002) Life History Evolution. Sinauer Associates, Inc., Sunderland, MA.

SALTHE, S. N. (1969) Reproductive modes and the number and sizes of ova in the urodeles. Am. Midl. Nat. 81: 467-490.

SINERVO, B., and BASOLO, A. L. (1996) Testing adaptation using phenotypic manipulations. Pp. $149-185$ in Adaptation. M. R. Rose and G. V. Lauder (eds.) Academic Press, San Diego, USA. 


\section{T. Landberg}

SINERVO, B., MCEDWARD, L. R., (1988) Developmental consequences of an evolutionary change in egg size: an experimental test. Evolution 42: $885-899$

SMITH, C. C. and FRETWELL, S. D. (1974). The optimal balance between size and number of offspring. Am. Nat. 499-506.

ULLER, T. (2008) Developmental plasticity and the evolution of parental effects. Trends Ecol Evol 23: 432-438.
VAN NOORDWIJK, AJ. and DE JONG, G. (1986) Acquisition and allocation of resources: their influence on variation in life history tactics. Am. Nat. 128: 137-142

WELLS, K.D. (2007) The ecology and behavior of amphibians. University of Chicago Press, Chicago, USA.

WINKLER, D. W., and WALLIN, K. (1986) Offspring size and number: a life history model linking effort per offspring and total effort. Am. Nat. 129: 708-720. 


\section{Further Related Reading, published previously in the Int. J. Dev. Biol.}

Sexual dimorphism of AMH, DMRT1 and RSPO1 localization in the developing gonads of six anuran species

Rafal P. Piprek, Anna Pecio, Katarzyna Laskowska-Kaszub,Jacek Z. Kubiak and Jacek M. Szymura

Int. J. Dev. Biol. (2013) 57: 891-895

Dual embryonic origin of the hyobranchial apparatus in the Mexican axolotl (Ambystoma mexicanum)

Asya Davidian and Yegor Malashichev

Int. J. Dev. Biol. (2013) 57: 821-828

Clonal analyses in the anterior pre-placodal region: implications for the early lineage bias of placodal progenitors

Sujata Bhattacharyya and Marianne E. Bronner

Int. J. Dev. Biol. (2013) 57: 753-757

Amphibian interorder nuclear transfer embryos reveal conserved embryonic gene transcription, but deficient DNA replication or chromosome segregation

Patrick Narbonne and John B. Gurdon

Int. J. Dev. Biol. (2012) 56: 975-986

Origins of $\mathrm{Cdx} 1$ regulatory elements suggest roles in vertebrate evolution

Stephen J. Gaunt and Yu-Lee Paul

Int. J. Dev. Biol. (2011) 55: 93-98

Reptile scale paradigm: Evo-Devo, pattern formation and regeneration

Cheng Chang, Ping Wu, Ruth E. Baker, Philip K. Maini, Lorenzo Alibardi and Cheng-Ming Chuong

Int. J. Dev. Biol. (2009) 53: 813-826

Proteomics analysis of regenerating amphibian limbs: changes during the onset of regeneration

Michael W. King, Anton W. Neff and Anthony L. Mescher

Int. J. Dev. Biol. (2009) 53: 955-969
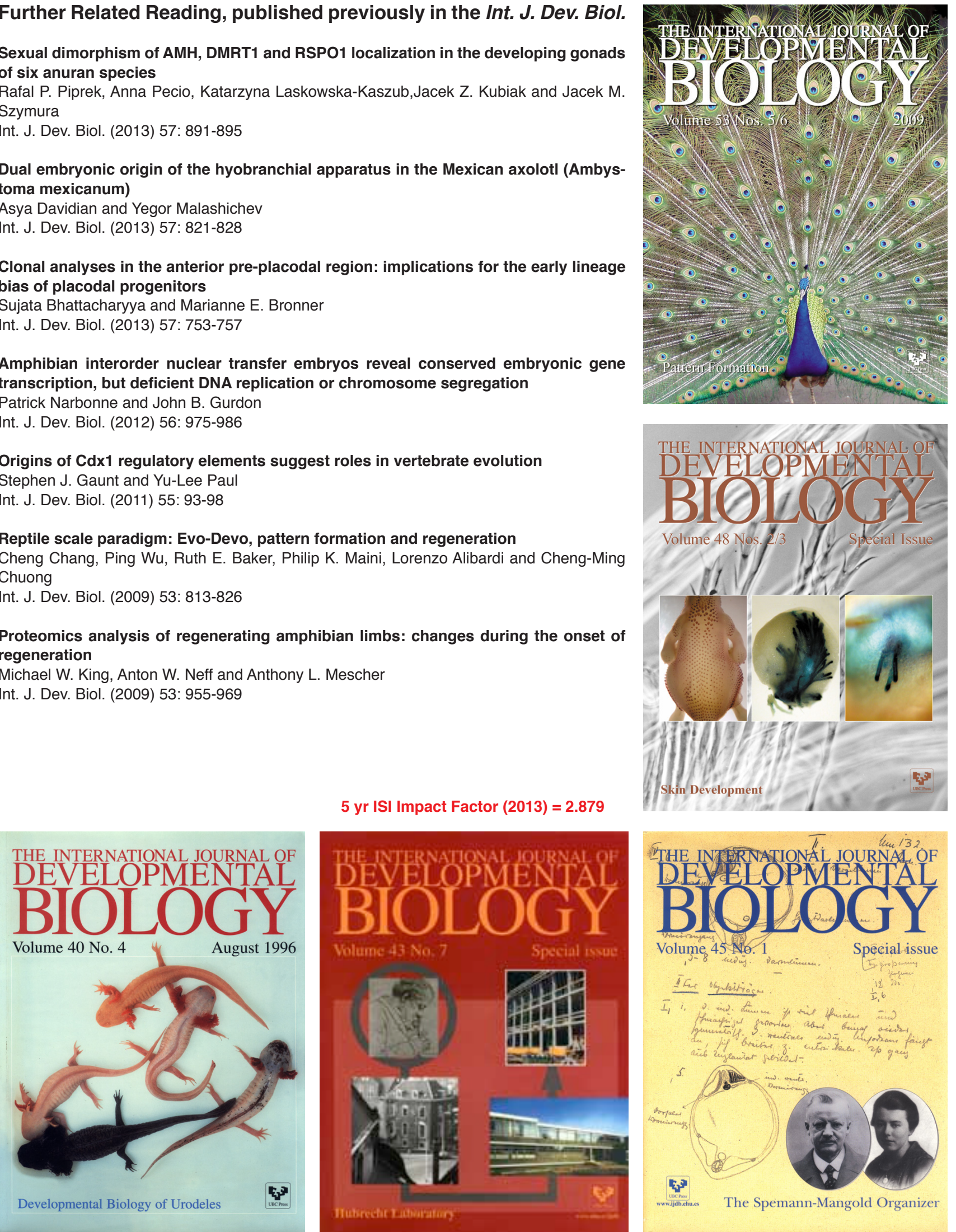

Volume 45 No. 1
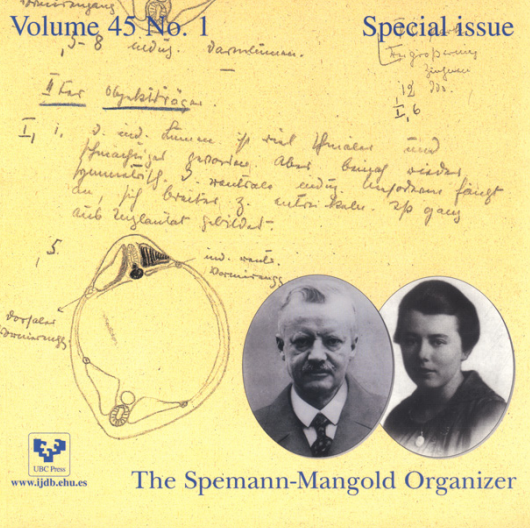